\title{
A note on root projection and labelling*
}

\section{Jochen Zeller}

Linguistics Programme, University of KwaZulu-Natal, Durban, South Africa

E-mail: zeller@ukzn.ac.za

\begin{abstract}
This paper identifies a problem with a hypothesis put forward in Chomsky (2013) in relation to his labelling algorithm. Chomsky suggests that category-neutral roots do not qualify as labels and cannot project. However, I provide evidence that the derivation of particle verbs involves the projection of a category-neutral root, which has merged with (a projection of) the particle. It follows that Chomsky's hypothesis has to be rejected.
\end{abstract}

Keywords: roots, projection, labelling, particle verbs

\section{Introduction}

A by now widely accepted assumption in syntactic theory is that the terminal nodes of morphosyntactic representations include category-neutral roots, which are categorised as verbs, nouns or adjectives in the context of specific functional heads. According to Chomsky (2013), these category-neutral roots cannot act as labels, and therefore lack the ability to project. However, I argue in this paper that verb-particle constructions pose a problem for this view. I demonstrate that particle verbs are formed by merging a category-neutral root with the projection of the particle, and that the resulting syntactic object is a projection of the root (i.e. an $\sqrt{R P}$ ). This contradicts Chomsky's claim that roots cannot project.

The concept of a category-neutral root is introduced in section 2. Section 3 discusses the labelling algorithm proposed in Chomsky (2013), which leads Chomsky to the hypothesis that

\footnotetext{
${ }^{*}$ I wish to thank Theresa Biberauer and Alex Andrason for their initiative in compiling this Festschrift. A special thanks goes to Johan for his collegiality and continued support during my life as a linguist in South Africa. Shortly after my arrival in the country, Johan invited me to give a talk at Stellenbosch University. He also invited me to stay at his house, cooked for me, and burnt me a CD with 60s rock music. The talk I gave during my visit to Stellenbosch was on particle verbs. It therefore seems appropriate to contribute to this Festschrift with a paper in which particle verbs play a significant role. This work is based on the research supported in part by the National Research Foundation of South Africa. Any opinion, finding and conclusion or recommendation expressed in this material is that of the author and the NRF does not accept any liability in this regard.
} 
roots do not qualify as labels. In section 4, I present counterevidence to this hypothesis by discussing the structure of particle verbs. Section 5 concludes.

\section{Category-neutral roots}

Distributed Morphology (DM; Halle \& Marantz 1993, and much subsequent work) views morphology as being "distributed" across different places in grammar. The computational system combines morphemes (roots and functional heads) to form structures via internal and external Merge. The terminal nodes of these structures are then supplied with phonological exponents (vocabulary items) and lexical-semantic interpretations (conceptual knowledge from the encyclopedia) in the mapping to the interfaces with the sensorymotor and the conceptualintentional interface ("late insertion").

A key assumption of DM, also shared by other frameworks, such as Borer's (2005) Exo-Skeletal model, is that syntactic roots are category-neutral and lack grammatical features (Marantz 1997; Harley 2014). Category-neutral roots are "typed" as verbs, nouns or adjectives in the local environment of category-defining functional heads ("little" $v, n$ and a) with which they merge. For example, a word such as love is not inherently a noun or a verb, but consists of the root $\sqrt{L O V E}$, which is categorised as a verb when it merges with $\mathrm{v}$, and which becomes a noun when it merges with $\mathrm{n}$ :

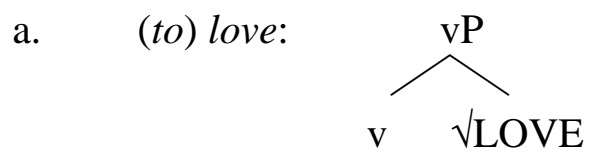

b. (the) love:

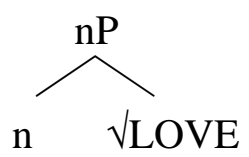

A consequence of this idea is that the result of the first application of Merge in a derivation (called "Primary Merge" in De Belder \& van Craenenbroeck 2015) is typically a syntactic object $\mathrm{SO}=\{\mathrm{R}, \mathrm{f}\}$, with $\mathrm{R}$ an acategorial root and $\mathrm{f}$ a category-defining functional head $\mathrm{v}, \mathrm{n}$ or a.

\section{Labelling}

A declared goal of the Minimalist Program is to reduce fundamental properties of language to so-called third factor principles (e.g. principles of efficient computation, such as minimal search). Chomsky (2013) offers a third-factor explanation of the property of projection (the identification of the category of a phrase) in terms of his labelling algorithm LA. Chomsky argues that, in order for an SO to be interpretable, it must be assigned a categorial label, because different categories give rise to different interpretations at the interfaces. LA is a fixed procedure which, for each SO formed by an application of Merge, selects a designated element from within SO as its label. According to Chomsky (2013), LA operates at the phase level and can be reduced to minimal search.

LA works straightforwardly when the $\mathrm{SO}$ is $\{\mathrm{H}, \mathrm{XP}\}$, formed by Merge of a head $\mathrm{H}$ and a phrase XP. Here LA will automatically select $\mathrm{H}$ as the label, as a result of minimal search. A more complicated case is the SO $\{\mathrm{XP}, \mathrm{YP}\}$, created via Merge of two phrases. Chomsky (2013) proposes two ways in which $\{\mathrm{XP}, \mathrm{YP}\}$ can be labelled. The first option is for XP to undergo internal Merge (i.e. movement), in which case its copy in $\{X P, Y P\}$ is no longer visible for LA, and $\mathrm{Y}$ is selected as the label. Alternatively, $\{\mathrm{XP}, \mathrm{YP}\}$ can be labelled if XP and YP share a 
feature. For example, when a subject DP merges with TP, LA selects the shared $\varphi$-features of DP and T as the label of \{DP, TP $\}$ (see Chomsky 2013 for further details).

A problem for LA arises with Primary Merge, which builds a phrase $\{\mathrm{H}, \mathrm{H}\}$ out of two heads. If both heads had grammatical features, then either head would qualify as a potential label, and it is not clear how LA could determine which one must project. For example, if the DP the man was formed by Primary Merge of $\mathrm{D}$ the and $\mathrm{N}$ man, then the resulting $\mathrm{SO}\{\mathrm{D}, \mathrm{N}\}$ would consist of two potential labels, and hence be "unlabelable". However, this is where the idea discussed in section 2 comes to the rescue, according to which a noun such as man is syntactically complex, consisting of the root $\sqrt{ }$ MAN and the functional head n. Crucially, Chomsky (2013: 46) suggests that a root "does not qualify as a label", a fact that, according to De Belder \& van Craenenbroek (2015), follows from the assumption that roots are devoid of any grammatical features that could be copied onto a higher node. This solves the problem raised by SOs of the form $\{\mathrm{H}, \mathrm{H}\}$ : if roots cannot be labels, then it follows that for any $\mathrm{SO}\{\mathrm{R}, \mathrm{f}\}$ consisting of a category-neutral root $\mathrm{R}$ and a functional categorising head $\mathrm{f}$, LA will automatically select $\mathrm{f}$ as the label.

However, if roots cannot act as labels, then this means that they cannot project. This in turn implies that roots can never take complements (cf. De Belder \& van Craenenbroeck 2015). But as I show in the next section, there is one type of construction which clearly involves Merge of a root and a complement: the particle verb.

\section{Particle verbs}

All Germanic languages have constructions in which a verbal base combines with a so-called particle (most often a prepositional element) to form a complex verb. The following are examples from English (2), German (3) and Afrikaans (4) (the examples in (4) are taken from Pretorius 2017):
a. cook up
b. play down
c. fall off

(3) a. anziehen (an-ziehen, on-pull), "put on, get dressed"

b. aufspringen (auf-springen, up-jump), "jump up"

c. beisteuern (bei-steuern, at-steer), "contribute"

(4) a. uithang (uit-hang, out-hang), "hang out"

b. omkoop (om-koop, around-buy), "bribe"

c. $\quad$ opvoed (op-voed, up-feed), "teach"

A well-known syntactic property of verb-particle constructions is that the particle can be separated from the verb in the syntax:

(5) Johan cooked it up. 
Johan zieht seine Jacke an.

Johan pulls his jacket on

"Johan puts on his jacket."
Johan hang die
wasgoed
Johan hangs the washing
"Johan hangs out the washing."

\author{
uit. \\ out.
}

Given the separability of the particle verb, most pre-DM analyses of verb-particle constructions treat the particle or its projection as a phrasal sister of the verb (see e.g. van Riemsdijk 1978; Den Dikken 1995; Zeller 2001, and many others). The spirit of this analysis has been maintained in DM. Basilico (2008), Harley (2009) and Deacon (2011) all suggest that the structure of particle verbs involves a category-neutral root which merges with (a projection of) the particle (represented as $\operatorname{Prt}(\mathrm{P})$ in (8)). ${ }^{1}$ The root is then categorised as a verb in the context of the category-defining functional head $\mathrm{v}$, which is merged next. Based on these proposals, I assume that a particle verb such as cook up in (2a) has the structure in (8):

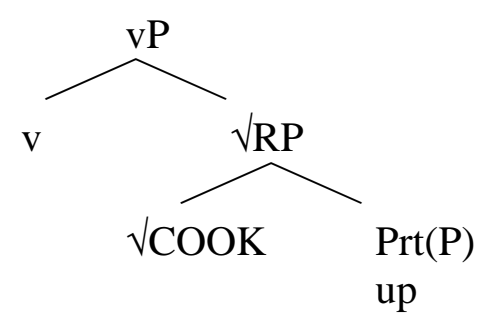

In (8), the SO formed by merging the root and Prt(P) is represented as a projection of the root (an $\sqrt{R P}$ ). However, this idea is incompatible with Chomsky's (2013) assumption that roots cannot act as labels and are unable to project.

An alternative analysis of the merger of the root $\mathrm{R}$ and the particle, which maintains the view that roots cannot project, would be to treat the particle as the label of the $\mathrm{SO}\{\mathrm{R}, \operatorname{Prt}(\mathrm{P})\}$. In this case, the node labelled $\sqrt{ } \mathrm{RP}$ in (8) would in fact be a PrtP, i.e. a projection of the particle. However, this alternative is problematic, since it implies that the root can no longer be categorised as a verb. Here is why: if the particle was the head of the $\mathrm{SO}\{\mathrm{R}, \operatorname{Prt}(\mathrm{P})\}$, then the complement of the categorising head $\mathrm{v}$ would be the PrtP, and the closest head to $\mathrm{v}$ would no longer be the root, but the particle (the head of v's complement). The root would have become a complement of Prt (or a specifier, if the particle is already phrasal before it merges with the root). The problem is that a category-defining head like v can only "type" elements in its local environment, i.e. its complement or the head $\mathrm{H}$ of its complement (which possibly undergoes head movement to combine with the categoriser), but not a specifier or a complement of $\mathrm{H}$. In other words, treating the particle as the label of the verb-particle combination would destroy the syntactic relation between the root and the category-defining head $\mathrm{v}$ that is required for the

\footnotetext{
${ }^{1} \operatorname{Prt}(\mathrm{P})$ in (8) (and below) may be a simple (possibly functional) element (Basilico 2008), or it may be a complex particle phrase formed by either merging the particle with an argument (Harley 2009), or by combining a categoryneutral root with a categorising "little" p head (Deacon 2011; Zeller 2017). In this short note, I do not commit myself to the exact syntactic status of the particle.
} 
root to be "typed" as a verb. This means that the only way in which the root in an SO of the form $\{\mathrm{R}, \operatorname{Prt}(\mathrm{P})\}$ can be verbalised is for the root to be selected as the label of this SO. ${ }^{2}$

To maintain the idea that roots cannot act as labels and cannot project, one could suggest that (8) is simply not the correct structure of verb-particle constructions. An alternative would be to assume that PrtP does not merge with the category-neutral root, but with its verbalised form, as shown in (9):

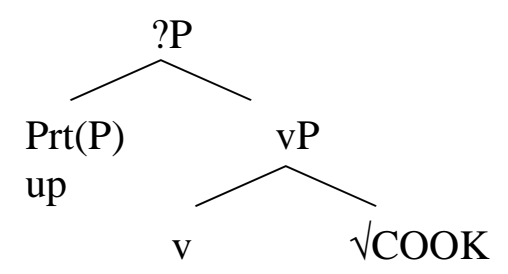

In (9), the root and v merge, and v projects. The particle is then merged with vP. However, even if we ignore the fact that the structure in (9) produces the wrong word order, (9) cannot be the correct structure of particle verbs. First of all, there are labelling problems with the SO $\{\operatorname{Prt}(\mathrm{P})$, $\mathrm{vP}$ \} in (9). To see why, consider what happens if the particle in (9) is analysed as a simple element. In this case, the particle becomes a head that merges with $\mathrm{vP}$, so LA will select it as the label, and the ?P in (9) would become a PrtP - clearly the wrong result. Next, consider what happens if the particle in (9) is treated as a complex phrase instead. Now the SO $\{$ PrtP, vP poses another problem for labelling, because neither PrtP nor vP is a head. Since the two phrases do not share a grammatical feature, and since neither phrase undergoes movement, this SO cannot be labelled. Therefore, even though the structure in (9) is consistent with the view that a root does not qualify as a label and cannot project, it raises labelling problems of a different sort.

There is also empirical evidence that particles are merged with bare roots, as in (8), and not with "typed" verbal structures, as in (9). The first piece of evidence is provided by the fact that verb-particle constructions license "contextual allosemy" of both the particle and the verb. The presence of a particle may give rise to "special meanings" of the root, which are different from the meaning of the root when it appears without a particle. For example, Basilico (2008) notes that to cook up an evil scheme does not imply a cooking-activity, and that drawing up a contract does not involve drawing. Furthermore, a preposition used as a particle may adopt a special meaning in the local context of the root that is not attested with the corresponding preposition. For example, the aspectual interpretation of up in particle verbs such as eat up or write up is not attested when up is used as a regular preposition.

In Zeller (2001), I show that the same kind of allosemy is found with German particle verbs. For example, the verb ziehen in (3a) takes on a special meaning that leads to a selectional restriction on its object, which has to be an item of clothing. This meaning also underlies the interpretation of other verb-particle constructions, such as (Kleider) ausziehen, 'take off (clothes)', (einen Hut) aufziehen, 'put on (a hat)', or (eine Jacke) überziehen, 'put on (a jacket as an extra layer)', but it is not a regular meaning of the verb ziehen when it appears without the

\footnotetext{
${ }^{2}$ Basilico (2008) argues that, when a particle merges with a root, it can optionally project. This means that in his analysis, the SO $\{\mathrm{R}, \operatorname{Prt}(\mathrm{P})\}$ can either be an $\sqrt{\mathrm{RP}}$ or a PrtP. However, Basilico does not address the question of how the root can be verbalised in the PrtP-structure, in which it is the complement of the particle.
} 
particle. Particle allosemy is even more pervasive in German; many prepositional particles have meanings that are not attested with the corresponding prepositions (see Stiebels 1996). For example, auf in German means "on" when used as a preposition (e.g. auf dem Tisch, "on the table"), but adopts an adverbial meaning "up" or "upward" when used as a particle, as e.g. in (3b).

Importantly, it is a fundamental assumption of DM that contextual allosemy (like contextual allomorphy) requires the licenser and the licensee of a special meaning to be part of the same local domain (see e.g. Marantz 1997, 2013, and many others). In this spirit, I argue in Zeller (2001) that a particle and a verb can license each other's allosemes because they are "structurally adjacent", i.e. the particle is the head of the verb's complement, and no functional material intervenes between the verb and the particle. Basilico (2008) makes essentially the same point, arguing that special meanings of a root can only be licensed by a particle in a structure such as (8), where the particle merges directly with the root. In contrast, Basilico notes that a particle would not be expected to have an effect on the interpretation of a root in a structure such as (9), because here, the root meaning is established in the context of little $\mathrm{v}$, which structurally blocks any interaction between the root and the particle when the latter is merged outside vP.

The second piece of empirical evidence that the structure of particle verbs involves the merger of a root and a particle (phrase) is provided by German root nominalisations based on particle verbs:
a. aufbrechen (up-break), "depart" - der Aufbruch, "the departure"
b. vorschreiben (in.front-write), "instruct" - die Vorschrift, "the instruction"
c. angreifen (on-grip), "attack" - der Angriff, "the attack"

The meaning of the nouns on the right hand side of (10) is clearly based on the (idiomatic) meaning of the particle verbs on the left. This suggests that the nouns in (10) are nominalisations of the corresponding particle verbs. However, the phonological properties of these nouns suggest otherwise: the nominal roots in (10) have the same irregular shape as the nominal roots corresponding to the simple verb forms in (11):
a. brechen, 'break' - der Bruch, "the break"
b. $\quad$ schreiben, 'write' - die Schrift, "the writing"
c. greifen, 'grip' - der Griff, "the grip, handle"

The fact that the pairs in (10) systematically show the same root allomorphy as the pairs in (11) suggests that the nouns in (10) are not nominalisations of particle verbs, but are instead derived by adding a particle to the root nominals in (11). ${ }^{3}$ The nouns in (10) hence represent a bracketing paradox; their semantic properties suggest that they have the structure in (12a), while their phonological properties suggest that they are formed as in (12b):
a. $\quad[\mathrm{N}[\mathrm{v}$ prt + verb] $]$
b. [N prt [N noun]]

\footnotetext{
${ }^{3}$ Note that "true" nominalisation of particle verbs preserves the verbal root allomorph, compare e.g. the noun Vorschrift in (10b) (based on the nominal root schrift) with the noun in (i) (based on the verbal root schreib-):

(i) ausschreiben (out-write), "advertise" - die Ausschreibung, "the advert"
} 
The advantage of the structure in (8) is that it offers a straightforward solution to this paradox. According to (8), the meaning of a particle verb is established in the domain of $\sqrt{R P}$, where the root and the particle are structurally adjacent, and the root is verbalised through the addition of little v. (13a) shows the corresponding structure for the German particle verb aufbrechen in (10a). In order to explain that the semantics of the noun Aufbruch in (10a) corresponds to the meaning of this particle verb (even though it is clearly formed with a nominal root), all that needs to be assumed is that $\sqrt{R P}$ in this example does not merge with little $\mathrm{v}$, but with little $\mathrm{n}$, as shown in (13b). Because the choice of the relevant root allomorph is determined by the local context of the category-defining heads, (13) explains why the verbal form of the root in (10a) is brech-, whereas the nominal form is bruch. But importantly, since the interpretation of both constructions is still established at the level of $\sqrt{R P}$, we can now see why the "particle noun" in (13b) has the same meaning as the particle verb in (13a): the underlying structure of $\sqrt{R P}$ is identical in both cases:

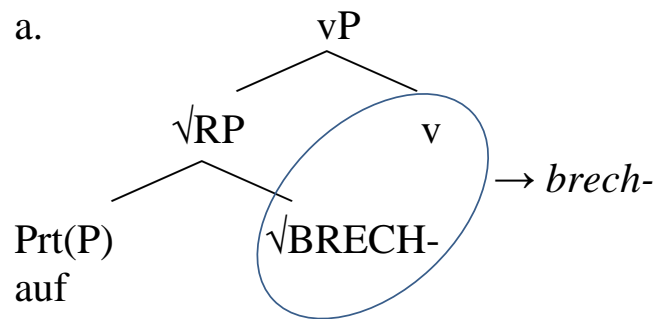

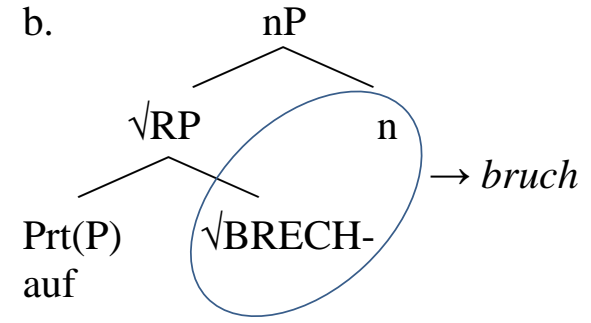

The assumption that roots can take particles as complements and project before they are categorised as verbs or nouns explains the semantic parallels between the particle verbs and the particle nouns in (10). In contrast, these parallels cannot be captured in a theory which postulates a structure such as (9) for particle verbs, since in this structure, the particle and the root do not appear in the same local environment.

\section{Conclusion}

In this paper, I have provided evidence that the syntax of particle verbs (and particle nouns) is based on a structure in which a root merges with a complement, and projects an $\sqrt{R P}$. I therefore conclude that Chomsky's (2013) hypothesis that roots do no qualify as labels is incorrect. It follows that the label of an SO of the form $\{\mathrm{R}, \mathrm{f}\}$ cannot be determined on the basis of this hypothesis. The reason for why LA selects $f$, and not $R$, as the label of $\{R, f\}$ if $f$ is a categorydetermining head must therefore be sought elsewhere.

\section{References}

Basilico, D. 2008. Particle verbs and benefactive double objects in English: high and low attachments. Natural Language and Linguistic Theory, 26: 731-773.

Borer, H. 2005. Structuring sense, Vol. 1: In name only. Oxford: Oxford University Press.

Chomsky, N. 2013. Problems of projection. Lingua, 130: 33-49.

Deacon, R.J. 2011. P-forms in Distributed Morphology: Accounting for a type of semilexical form. Master's thesis. Gainesville: University of Florida. 
De Belder, M. \& J. van Craenenbroeck. 2015. How to merge a root. Linguistic Inquiry, 46(4): 625-655.

Den Dikken, M. 1995. Particles. On the Syntax of Verb-Particle, Triadic, and Causative Constructions. New York and Oxford: Oxford University Press.

Halle, M. \& A. Marantz. 1993. Distributed morphology and the pieces of inflection. In K. Hale and S.J. Keyser (eds.) The View from Building 20: Essays in Linguistics in Honor of Sylvain Bromberger. Cambridge: MIT Press. pp. 111-176.

Harley, H. 2009. The morphology of nominalizations and the syntax of $v$ P. In A. Giannakidou and M. Rathert (eds.) Quantification, Definiteness, and Nominalization. Oxford: Oxford University Press. pp. 321-343.

Harley, H. 2014. On the identity of roots. Theoretical Linguistics, 40: 225-276.

Marantz, A. 1997. No escape from syntax: don't try morphological analysis in the privacy of your own lexicon. UPenn Working Papers in Linguistics, 4: 201-225.

Marantz, A. 2013. Locality domains for contextual allomorphy across the interfaces. In O. Matushansky and A. Marantz (eds.) Distributed Morphology Today. Morphemes for Morris Halle. Cambridge: MIT Press. pp. 95-115.

Pretorius, E. 2017. Spelling Out P. A Unified Syntax of Afrikaans Adpositions and V-Particles. Utrecht: LOT.

Riemsdijk, H. v. 1978. A Case Study in Syntactic Markedness. Dordrecht: Foris.

Stiebels, B. 1996. Lexikalische Argumente und Adjunkte. Berlin: Akademie Verlag.

Zeller, J. 2001. Particle verbs and Local Domains. Amsterdam: John Benjamins.

Zeller, J. 2017. Particle verb nominalisation and particle nouns. Talk given at SAMWOP-6, University of Stellenbosch, November 2017. 